\title{
JRAK
}

JURNAL RISET

AKUNTANSI

VOLUME 6 NO 2

JULI 2020

DAN BISNIS

jrak@plb.ac.id

\section{IMPLEMENTASI DIGITAL MARKETING DAN KEUNGGULAN BERSAING UNTUK MENDUKUNG KEBERHASILAN UMKM DI KOTA BANDUNG}

\author{
Heppy Agustiana V - STIE Ekuitas
}

\begin{abstract}
ABSTRAK
Tujuan dari penelitian ini adalah mengetahui dan menganalisis persepsi UMKM di kota Bandung mengenai implementasi digital marketing dan keunggulan bersaing dalam mendukung keberhasilan usaha. Metode penelitian yang digunakan adalah penelitian kuantitatif dengan instrument penelitian kuesioner yang dibagikan pada 100 UMKM Skala Mikro yang ada di kota Bandung dengan teknik simple random sampling. Penelitian ini sejalan dengan Renstra STIE Ekuitas, yaitu mengenai $e$-commerce, analisis riset prilaku produsen khususnya dalam melihat pemanfaatan digital marketing. .Hasil dari penelitian ini diperoleh bahwa digital marketing, keunggulan bersaing dan keberhasilan usaha dalam kategori baik. Digital marketing keunggulan bersaing mempunyai pengaruh pada keberhasilan usaha.
\end{abstract}

Kata kunci : Digital Marketing, Keunggulan Bersaing, Keberhasilan Usaha, UMKM

\section{PENDAHULUAN}

Pada era milenial saat ini, perkembangan zaman semakin pesat dari hari ke hari. Hal ini menimbulkan pertumbuhan bisnis, sistem perekonomian dan salah satunya adalah teknologi yang semakin maju. Perkembangan jumlah pengguna internet yang tiap tahun mengalami pertumbuhan ini menunjukkan dengan teknologi terjadi perubahan prilaku konsumen, termasuk prilaku seseorang dalam mengkonsumsi suatu barang, dengan melakukan pencarian di dunia maya.

Data di bawah ini juga menunjukkan jumlah pengguna internet di Indonesia 


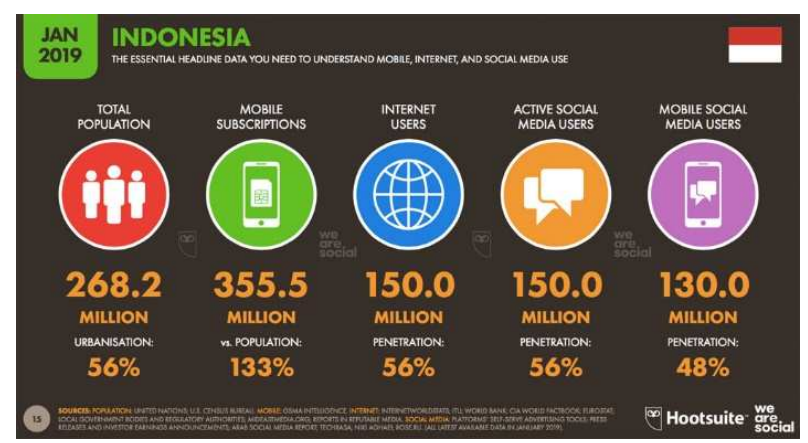

Gambar 1. Jumlah Pengguna Internet di Indoesia pada tahun 2019.

Dari Gambar 1 dijelaskan tinggnya pengguna internet sehingga menimbulkan perubahan prilaku baik dalam mengkonsumsi maupun memproduksi suatu barang ataupun jasa. Pesatnya perkembangan teknologi, dunia digital dan internet tentu juga berimbas pada dunia pemasaran. Tren pemasaran di dunia beralih dari yang semula konvensional (offline) menjadi digital (online). Digital marketing adalah kegiatan promosi dan pencarian pasar melalui media digital secara online dengan memanfaatkan berbagai sarana misalnya jejaring sosial.

Usaha Mikro, Kecil dan Menengah (UMKM) memiliki peran penting dalam laju ekonomi Indonesia terutama dalam penciptaan lapangan kerja dan pemberdayaan rumah tangga yang mendukung pendapatan rumah tangga. Keberadaan UMKM diharapkan mampu memacu perekonomian di tengah perlambatan ekonomi yang terjadi saat ini. Pemanfaatan konsep pemasaran berbasis teknologi digital (digital marketing) memberikan harapan bagi UMKM untuk berkembang menjadi pusat kekuatan ekonomi.

Berdasarkan data dari kepala Dinas koperasi Usaha Mikro kecil dan Menengah (UMKM) kota Bandung Bapak Priana Wira Saputra, berdasarkan data yang diperoleh dari Badan Pusat Statistik, kota Bandung memiliki 300 ribu UMKM, tingginya angka tersebut memberikan peluang bagi pertumbuhan ekonomi di kota Bandung, oleh karena itu dinas UMKM mendorong para UMKM untuk memasarkan produknya secara online, dengan pemasaran digital produk mereka akan jauh lebih dikenal masyarakat luas. Tantangan kontinuitas dan kualitas produk yang dapat dihadapi dengan baik akan membuat UMKM sukses dan cepat berkembang.

Tujuan penelitian ini memperoleh hasil kajian pengaruh implementasi digital marketing dan keunggulan bersainguntuk mendukung keberhasilan usaha UMKM Skala Mikro di kota Bandung.

\section{LANDASAN TEORI}

\section{Konsep Digital Marketing}

Definisi digital marketing menurut American Marketing Association (AMA) adalah aktivitas, institusi, dan proses yang difasilitasi oleh teknologi digital dalam menciptakan, mengomunikasikan, dan menyampaikan nilai-nilai kepada konsumen dan pihak yang berkepentingan lainnya (Kannan \& Hongshuang, 2016). Chaffey (2013) mendefinisikan digital marketing sebagai penggunaan teknologi untuk membantu aktivitas pemasaran yang bertujuan untuk meningkatkan pengetahuan konsumen dengan cara menyesuaikan dengan kebutuhan mereka. Sawicky (2016) mengartikan digital marketing sebagai eksploitasi terhadap teknologi 
digital yang digunakan untuk menciptakan suatu saluran untuk mencapai resipien potensial untuk mencapai tujuan perusahaan melalui pemenuhan kebutuhan konsumen yang lebih efektif. Pemasaran online juga dikenal sebagai digital marketing, pemasaran web, pemasaran digital, mesin pencari pemasaran serta promosi pemasaran kepada konsumen. Digital marketing dianggap efektif untuk diterapkan oleh UMKM dalam memasarkan produknya. Mujiana dan Abdul (2012) mengatakan, salah satu daya saing yang harus dimiliki oleh UMKM adalah penguasaan teknologi informasi. Digital marketing dapat menjadi peluang bagi UMKM dalam mendapatkan perhatian konsumen. Icha (2016) juga menyatakan bahwa cara tercepat untuk mendapatkan perhatian dari konsumen dan dengan berbagai macam cara di mana organisasi telah ditemukan untuk terhubung dengan konsumen mereka adalah melalui media sosial. Purwana et al. (2017) menyatakan lebih lanjut bahwa digital marketing adalah kegiatan promosi dan pencarian pasar melalui media digital secara online dengan memanfaatkan berbagai sarana misalnya jejaring sosial. Pengukuran Digital marketing menurut http;//www.mercedes-benz.com/provider Website Strategy, adalah ketika mengimplementasikan website strategy menggunakan great content SEO, menggunakan Email Strategy, menggunakan database palenggan dan Social Media Strategy, yaitu penggunaan Facebook, Twitter, Instagram, Youtube.

\section{Konsep Keunggulan Bersaing}

Dogre dan Vickrey,1994,p.669-670 . Bharadwaj et al.,( 1993,p83-84 )menjelaskan bahwa Keahlian dan asset yang unik dipandang sebagai sumber dari keunggulan bersaing. Pendapat yang serupa juga dikemukakan oleh Porter ( 1990,p.3 ) yang menjelaskan bahwa keunggulan bersaing adalah jantung kinerja pemasaran untuk menghadapi persaingan. Menampilkan suatu produk yang lebih unik yang sesuai dengan keinginan pelanggan merupakan pemberian nilai lebih yang diberikan kepada pelanggan (Godfrey dan Hill, 2013). Rosli (2012) menyatakan bahwa keunggulan bersaing bagi UKM sangat ditentukan oleh kemampuan UKM tersebut dalam mengantisipasi globalisasi. Pengukuran keunggulan bersaing bagi UKM menggunakan indikator dynamic capabilities, innovation, dan global orientation.

\section{Konsep Keberhasilan Usaha}

Menurut Purnama dan Suyanto (2010), keberhasilan industri kecil dipengaruhi oleh berbagai faktor. Sebuah bisnis yang sukses ketika meningkat keuntungan, meskipun keuntungan bukan satu-satunya aspek dalam nilai keberhasilan bisnis (Suarmawan 2015). Hasan et al. (2012) mengatakan, kriteria klasifikasi untuk sukses terbentuk dari pengukuran keberhasilan pengusaha baru terdiri dari berbagai pasar, jaringan bisnis, pendapatan bulanan, nilai aset, berbagai produk, bisnis lama bertahan hidup, inovasi, dan hak kekayaan intelektual.

\section{METODOLOGI PENELITIAN}

Metode penelitian ini menggunakan menggunakan jenis penelitian kuantitatf yaitu penelitian deskriptif verifikatif dengan instrument penelitian berupa kuesioner yang dibagikan kepada UMKM Skala Mikro yang berada di Bandung. Untuk Variabel Digital Marketing (X1) terdiri dari 6 indikator, Keunggulan Bersaing ( X2) terdiri dari 4 indikator dan variabel keberhasilan usaha ( $\mathrm{Y}$ ), terdiri dari 5 indikator. Kuesioner dibuat dengan menggunakan skala ordinal 5 dimanal sangat tidak setuju dan 5 sangat setuju ( Sekaran and Bougie,2016). Uji 
validitas menggunakan produk momen dan uji reliabilitas menggunakan cronbach alfa Sumber data yang diperoleh adalah data sekunder dan data primer. Sumber informasi data primer didapat dari UMKM Skala Mikro yang berada di kota Bandung. Sedangkan data sekunder adalah informasi yang dihimpun dari publikasi pemerintah,BPS dan hasil analisis media, website, laporan lembaga survey internasional dan nasional. Unit analisis dalam penelitian ini adalah 100 UMKM yang berada di kota bandung Analisis data kuantitatf dengan menggunakan analisis deskriptof dan analiisis verifikatif. Analisis Data deskriptif ini diterapkan untuk memperoleh gambaran mengenai variabel yang akan diteliti dari hasil kuesioner. Analisis Data Verifikatif menggunakan analisis regresi linier berganda

\section{PEMBAHASAN}

Bagian ini menyajikan hasil dari survey mengenai karakteritik UMKM Skala Mikro, analisa deskriptif dan analisa veriifikatif melalui regrei linier berganda

\section{Tabel 1. Karakteristik UMKM Skala Mikro}

\begin{tabular}{|c|c|c|c|}
\hline No & Uraian & Jumlah & Prosentase \\
\hline \multicolumn{4}{|c|}{1 Jenis kelamin } \\
\hline & a. Pria & 42 & $42 \%$ \\
\hline & b. wanita & 58 & $58 \%$ \\
\hline \multicolumn{4}{|c|}{2 Usia } \\
\hline & a. $<20$ th & 8 & $8 \%$ \\
\hline & b. $21-30$ th & 57 & $57 \%$ \\
\hline & c. $31-40$ th & 11 & $11 \%$ \\
\hline & d. $41-50$ th & 22 & $22 \%$ \\
\hline & e. $>50$ th & 2 & $2 \%$ \\
\hline \multicolumn{4}{|c|}{3 Penghasilan } \\
\hline & a. $500.000-2.000 .000$ & 47 & $47 \%$ \\
\hline & b. $2.100 .000-5.000 .000$ & 32 & $32 \%$ \\
\hline & c. $5.100 .000-10.000 .000$ & 17 & $17 \%$ \\
\hline & d.Di atas 10.000 .000 & 4 & $4 \%$ \\
\hline
\end{tabular}

Sumber : Hasil Pengolahan Data Primer, 2020

Berdasarkan data daari tabel 1 dapat diketahui bahwa Kepemilikan UMKM lebih banyak wanita, Sebagian besar wisatawan berusia 21 - 30 tahun dan memiliki penghasilan per bulannya yaitu $500.000-2.000,000$

\section{Hasil Analisis Deskriptif}

Tanggapan UMKM Skala Mikro mengenai Variabel Digital Marketing (X1), dapat di lihat pada tabel berikut ini : 
Tabel 2. Tanggapan UMKM Skala Mikro Mengenai Variabel Digital Marketing (X1)

\begin{tabular}{|c|c|c|c|c|c|c|c|c|}
\hline \multirow{2}{*}{ Variabel } & \multirow{2}{*}{\multicolumn{2}{|c|}{ Indikator }} & \multicolumn{5}{|c|}{ Alternatif Jawaban } & \multirow{2}{*}{ Total Skor } \\
\hline & & & 1 & 2 & 3 & 4 & 5 & \\
\hline \multirow{6}{*}{$\begin{array}{c}\text { Digital } \\
\text { Marketing } \\
\text { (X1) }\end{array}$} & $\mathrm{X} 1.1$ & $\begin{array}{l}\text { Implementasi penggunaan } \\
\text { website }\end{array}$ & 10 & 12 & 22 & 30 & 26 & 350 \\
\hline & $\mathrm{X} 1.2$ & $\begin{array}{l}\text { Sudah ada di pencariaan } \\
\text { google }\end{array}$ & 21 & 14 & 27 & 20 & 18 & 300 \\
\hline & $\mathrm{X} 1.3$ & $\begin{array}{l}\text { Mencantumkan alamat } \\
\text { email di produk yang di } \\
\text { jual }\end{array}$ & 14 & 9 & 17 & 27 & 33 & 356 \\
\hline & $\mathrm{X} 1.4$ & $\begin{array}{l}\text { Menggunakan email } \\
\text { customer untuk promosi }\end{array}$ & 16 & 19 & 23 & 21 & 21 & 312 \\
\hline & $\mathrm{X} 1.5$ & Sudah menggunakan FB & 9 & 11 & 15 & 27 & 38 & 374 \\
\hline & $\mathrm{X} 1.6$ & Sudah menggunakan Ig & 9 & 3 & 7 & 18 & 63 & 423 \\
\hline \multicolumn{8}{|c|}{ Rata-rata Keseluruhan } & 352.5 \\
\hline
\end{tabular}

Sumber : Hasil Pengolahan Data Primer, 2020

Berdasarkan Tabel 2 dapat dijelaskan bahwa UMKM Skala Mikro menilai variabel Digital Marketing (X1) dengan rentang nilai antara 312 - 423. Nilai rata-rata keseluruhan dari variabel Digital Marketing (X1) yaitu 352,5.termasuk kategori baik

\section{Tanggapan UMKM Skala Mikro Mengenai Variabel Keunggulan Bersaing (X2)}

Tanggapan UMKM Skala Mikro mengenai Variabel Keunggulan Bersaing (X2), dapat di lihat pada tabel berikut ini :

Tabel 3. Tanggapan UMKM Skala Mikro Mengenai Variabel Keunggulan Bersaing (X2)

\begin{tabular}{|c|c|c|c|c|c|c|c|c|}
\hline \multirow{2}{*}{ Variabel } & \multirow{2}{*}{\multicolumn{2}{|c|}{ Indikator }} & \multicolumn{5}{|c|}{ Alternatif Jawaban } & \multirow{2}{*}{ Total Skor } \\
\hline & & & 1 & 2 & 3 & 4 & 5 & \\
\hline \multirow{4}{*}{$\begin{array}{c}\text { Keunggulan } \\
\text { Bersaing } \\
\text { (X1) }\end{array}$} & $\mathrm{X} 1.1$ & $\begin{array}{l}\text { keunkan dibanding produk } \\
\text { pesaing }\end{array}$ & 3 & 5 & 21 & 33 & 38 & 398 \\
\hline & $\mathrm{X} 1.2$ & $\begin{array}{l}\text { Harga lebih rendah } \\
\text { dibandingkan pesaing }\end{array}$ & 5 & 12 & 22 & 35 & 26 & 365 \\
\hline & $\mathrm{X} 1.3$ & $\begin{array}{l}\text { UMKM Anda selalu } \\
\text { memberikan inovasi }\end{array}$ & 3 & 2 & 24 & 36 & 35 & 398 \\
\hline & $\mathrm{X} 1.4$ & $\begin{array}{l}\text { Adanya layanan tambahan } \\
\text { meningkatkan nilai bagi }\end{array}$ & 4 & 4 & 17 & 34 & 41 & 404 \\
\hline \multicolumn{8}{|c|}{ Rata-rata Keseluruhan } & 391.25 \\
\hline
\end{tabular}

Sumber : Hasil Pengolahan Data Primer, 2020

Berdasarkan Tabel 3 dapat dilihat konsumen menilai variabel Inovasi Produk (X2) dengan rentang nilai antara 365 - 398. Nilai rata-rata keseluruhan dari variabel Keunggulan Bersaing (X2) yaitu 391,5 termasuk dalam kategori baik

\section{Tanggapan UMKM Skala Mikro Mengenai Variabel Keberhasilan Usaha (Y)}


Tanggapan UMKM Skala Mikro mengenai Variabel Keberhasilan Usaha (Y), dapat di lihat pada tabel berikut ini :

Tabel 4. Tanggapan UMKM Skala Mikro Mengenai Keberhasilan Usaha (Y)

\begin{tabular}{|c|c|c|c|c|c|c|c|c|}
\hline \multirow{2}{*}{ Variabel } & \multirow{2}{*}{\multicolumn{2}{|c|}{ Indikator }} & \multicolumn{5}{|c|}{ Alternatif Jawaban } & \multirow{2}{*}{ Total Sko } \\
\hline & & & 1 & 2 & 3 & 4 & 5 & \\
\hline \multirow{5}{*}{$\begin{array}{l}\text { Keberhasilan } \\
\text { Usaha (X1) }\end{array}$} & $\mathrm{X} 1.1$ & Peningkatan omzet & 5 & 7 & 25 & 35 & 28 & 374 \\
\hline & $\mathrm{X} 1.2$ & Memiliki Citra yang baik & 3 & 3 & 11 & 38 & 45 & 419 \\
\hline & $\mathrm{X} 1.3$ & Terdapat efisiensi di produksi & 4 & 5 & 24 & 40 & 27 & 381 \\
\hline & $\mathrm{X} 1.4$ & Jaringan bisnis bertambah & 4 & 6 & 16 & 38 & 36 & 396 \\
\hline & $\mathrm{X} 1.5$ & Nilai aset bertambah & 2 & 5 & 24 & 34 & 35 & 395 \\
\hline \multicolumn{8}{|c|}{ Rata-rata Keseluruhan } & 393 \\
\hline
\end{tabular}

Sumber : Hasil Pengolahan Data Primer, 2020

Berdasarkan Tabel 4 dapat dilihat bahwa UMKM Skala Mikro menilai variabel Keberhasilan usaha (Y) dengan rentang nilai antara 374 - 419. Nilai rata-rata keseluruhan dari variabel Keberhasilan Usaha (Y) yaitu 393 termasuk dalam kategori baik.

\section{Analisis Verifikatif}

Tabel 5. Analisis Regresi Berganda

Coefficients $^{\mathrm{a}}$

\begin{tabular}{|c|c|c|c|c|c|c|c|c|}
\hline & \multirow[b]{2}{*}{ Model } & \multicolumn{2}{|c|}{$\begin{array}{c}\text { Unstandardized } \\
\text { Coefficients }\end{array}$} & \multirow{2}{*}{$\begin{array}{c}\begin{array}{c}\text { Standardized } \\
\text { Coefficients }\end{array} \\
\text { Beta }\end{array}$} & \multirow[b]{2}{*}{$\mathrm{t}$} & \multirow[b]{2}{*}{ Sig. } & \multicolumn{2}{|c|}{ Collinearity Statistics } \\
\hline & & $\mathrm{B}$ & Std. Error & & & & Tolerance & VIF \\
\hline \multirow[t]{3}{*}{1} & (Constant) & 3.784 & 1.325 & & 2.855 & .005 & & \\
\hline & Digital Marketing & .078 & .050 & .112 & 1.556 & .123 & .774 & 1.291 \\
\hline & Keunggulan Bersaing & .908 & .090 & .724 & 10.104 & .000 & .774 & 1.291 \\
\hline
\end{tabular}

a. Dependent Variable: Keberhasilan Usaha

Berdasarkan hasil perhitungan pada tabel 5, diperoleh bentuk persamaan regresi linier berganda sebagai berikut :

$$
\mathrm{Y}=0,3784+0,078 \mathrm{X}_{1}+\mathbf{0 , 9 0 8} \mathrm{X}_{2}+e
$$

Nilai koefisien regresi pada variabel-variabel bebasnya menggambarkan apabila diperkirakan variabel bebasnya naik sebesar satu unit dan nilai variabel bebas lainnya diperkirakan konstan atau sama dengan nol, maka nilai variabel terikat diperkirakan bisa naik atau bisa turun sesuai dengan tanda koefisien regresi variabel bebasnya.

Berdasarkan persamaan tersebut diketahui bahwa koefisien regresi digital marketing $\left(b_{1}\right)$ dan keunggulan bersaing $\left(b_{2}\right)$ memiliki koefisien regresi positif. Hal tersebut berarti digital 
marketing $\left(\mathrm{b}_{1}\right)$ dan keunggulan bersaing $\left(\mathrm{b}_{2}\right)$ memiliki pengaruh secara positif terhadap minat beli (Y).

Dari hasil persamaan regresi linear berganda, terdapat nilai konstanta $(\alpha)$ sebesar 0,378 artinya jika variabel digital marketing dan keunggulan bersaing $=0$, maka nilai variabel terikat akan bernilai sebesar 0,378. Dengan kata lain, apabila digital marketing dan keunggulan bersaing tidak memberikan pengaruh maka keputusan pembelian akan bernilai sebesar 0,378. Namun, apabila pada variabel digital marketing dan keunggulan bersaing $=5$, maka variabel terikat juga pasti akan meningkat, artinya jika digital marketing yang dilakukan baik dan keunggulan bersaing selalu yang dilakukan maka akan berdampak pada meningkatnya keberhasilan usaha dari UMKM Skala Mikro tersebut. Tanda koefisien regresi variabel bebas menunjukkan arah hubungan dari variabel yang bersangkutan dengan Keberhasilan Usaha.

Koefisien regresi untuk variabel bebas $\mathrm{X}_{1}$ bernilai positif, menunjukkan adanya hubungan yang searah antara Digital Marketing $\left(\mathrm{X}_{1}\right)$ dengan Keputusan Pembelian (Y). Koefisien regresi variabel $\mathrm{X}_{1}$ sebesar 0,078 mengandung arti untuk setiap kenaikan Digital Marketing $\left(\mathrm{X}_{1}\right)$ sebesar satu satuan akan menyebabkan meningkatnya Keberhasilan usaha (Y) sebesar 0,078 satuan. Artinya, apabila digital marketing meningkat maka keberhasilan usaha UMKM Skala Mikro juga akan meningkat. Dengan ini dapat menyimpulkan bahwa Digital maketing berpengaruh terhadap Keberhasilan Usha, untuk itu UMKM Skala Mikro perlu memiliki penerapan digital marketing agar keberhasilan usaha dari UMKM dapat tercipta. Untuk menerapkan digital marketing yang positif UMKM Skala Mikro harus melakukan penggunaan website, nama produk sudah ada di search engine di google, mencantumkan alamat email untuk produk yang dijual, menggunakan email customer untuk mempromosikan produk, sudah menggunakan $\mathrm{Fb}$ dan instagram untuk pemasaran online.

Koefisien regresi untuk variabel bebas $\mathrm{X}_{2}$ bernilai positif, menunjukkan adanya hubungan yang searah antara keunggulan bersaing $\left(\mathrm{X}_{2}\right)$ dengan Keberhasilan usaha (Y). Koefisien regresi variabel $\mathrm{X}_{2}$ sebesar 0,908 mengandung arti untuk setiap kenakan keunggulan bersaing $\left(\mathrm{X}_{2}\right)$ sebesar satu satuan akan menyebabkan meningkatnya keberhasilan usaha (Y) sebesar 0,908 satuan. Artinya, apabila keunggulan bersaing meningkat maka Keberhasilan usaha juga akan meningkat. Dengan ini dapat disimpulkan bahwa keunggulan bersaing berpengaruh terhadap Keberhasilan usaha. Untuk itu UMKM Skala Mikro harus memahami bahwa keberhasilan usaha akan didapatkan ketika memiliki keunggulan bersaing yaitu memiliki keunikan dibanding produk pesaing, memiliki harga yang lebih rendah dengan pesaing, selalu memberikan inovasi dan adanya layanana tambahan yang selalu memberikan nilai bagi pelanggannya.

Pengujian secara parsial dilakukan untuk membuktikan apakah secara parsial Digital Marketing dan keunggulan bersaing berpengaruh signifikan terhadap keberhasilan Usaha (Y). Untuk menguji hipotesis masing-masing variabel bebas digunakan statistik uji $t$ dengan melihat besarnya p-value (sig) dibandingkan dengan 0,05 (taraf signifikansi $\alpha=5 \%$ ).

\section{Pengujian Pengaruh Digital Marketing (X1) terhadap Keberhasilan Usaha (Y)}

Analisis pengaruh variabel Digital marketing $\left(\mathrm{X}_{1}\right)$ terhadap Keberhasilan Usaha (Y) diperoleh hasil berdasarkan hasil perhitungan dengan software SPSS sebagai berikut: 
Tabel 6. Pengaruh Digital Marketing $\left(\mathbf{X}_{1}\right)$ terhadap Keberhasilan Usaha (Y) Coefficients $^{\mathrm{a}}$

\begin{tabular}{|c|c|c|c|c|c|c|c|c|}
\hline \multirow{2}{*}{\multicolumn{2}{|c|}{ Model }} & \multicolumn{2}{|c|}{$\begin{array}{c}\text { Unstandardized } \\
\text { Coefficients }\end{array}$} & \multirow{2}{*}{$\begin{array}{c}\begin{array}{c}\text { Standardized } \\
\text { Coefficients }\end{array} \\
\text { Beta } \\
\end{array}$} & \multirow[b]{2}{*}{$\mathrm{t}$} & \multirow[b]{2}{*}{ Sig. } & \multicolumn{2}{|c|}{ Collinearity Statistics } \\
\hline & & B & Std. Error & & & & Tolerance & VIF \\
\hline \multirow[t]{3}{*}{1} & (Constant) & 3.784 & 1.325 & & 2.855 & .005 & & \\
\hline & Digital Marketing & .078 & .050 & .112 & 1.556 & .123 & .774 & 1.291 \\
\hline & $\begin{array}{l}\text { Keunggulan } \\
\text { Bersaing }\end{array}$ & .908 & .090 & .724 & 10.104 & .000 & .774 & 1.291 \\
\hline
\end{tabular}

a. Dependent Variable: Keberhasilan Usaha

Berdasarkan Tabel 6 dapat diketahui bahwa arah hubungan Digital Marketing $\left(\mathrm{X}_{1}\right)$ dengan Keberhasilan Usaha (Y) adalah positif (perhatikan nilai pada kolom unstandardize $B$ ), disana tertulis 0,078 artinya ketika ada peningkatan Digital Marketing $\left(\mathrm{X}_{1}\right)$ maka akan meningkatkan Keberhasilan Usaha (Y).

Kemudian penulis melakukan pengujian hipotesis menggunakan uji t dengan melihat besarnya t hitung dibandingkan dengan $\mathrm{t}$ tabel (taraf signifikansi $\alpha=10 \%$ ) kriteria pengujian yang digunakan adalah :

$>$ Jika $\mathrm{t}$ hitung $>\mathrm{t}$ tabel $(1,296)$ maka $\mathrm{H}_{0}$ ditolak dan $\mathrm{H}_{1}$ diterima.

$>$ Jika $\mathrm{t}$ hitung $<\mathrm{t}$ tabel $(1,296)$ maka $\mathrm{H}_{0}$ diterima dan $\mathrm{H}_{1}$ ditolak.

Berdasarkan ketentuan yang telah dikemukakan sebelumnya, dimana diperoleh t-hitung sebesar 1,556 dan derajat bebas (n-k-1) atau 100-2-1 = 97 diperoleh angka t tabel 1,296, sehingga t-hitung $>$ t-tabel. Artinya $\mathrm{H}_{01}$ ditolak dan $\mathrm{Ha}_{1}$ diterima, maka terdapat pengaruh signifikan antara Digital Marketing terhadap Keeberhasilan Usaha (Hipotesis 1 diterima).

Hal ini berarti menjelaskan bahwa semakin baik pelaksanaan/ implementasi digital marketing melalui maka keberhasilan usaha dari UMKM akan semakin meningkat . harus melakukan penggunaan website, nama produk sudah ada di search engine di google, mencantumkan alamat email untuk produk yang dijual, menggunakan email customer untuk mempromosikan produk, sudah menggunakan $\mathrm{Fb}$ dan instagram untuk pemasaran online.

\section{Pengujian Pengaruh Keunggulan Bersaing $\left(\mathbf{X}_{2}\right)$ terhadap Keberhasilan Usaha (Y)}

Analisis pengaruh variabel Keunggulan bersaing $\left(\mathrm{X}_{2}\right)$ terhadap Keberhasilan Usaha $(\mathrm{Y})$ diperoleh hasil berdasarkan hasil perhitungan dengan software SPSS sebagai berikut; 
Tabel 7 Pengaruh Keunggulan Bersaing $\left(\mathbf{X}_{2}\right)$ terhadap Keberhasilan Usaha (Y) Coefficientsa

\begin{tabular}{|c|c|c|c|c|c|c|c|c|}
\hline \multirow{2}{*}{\multicolumn{2}{|c|}{ Model }} & \multicolumn{2}{|c|}{ Unstandardized Coefficients } & \multirow{2}{*}{$\begin{array}{l}\text { Standardized } \\
\text { Coefficients } \\
\text { Beta }\end{array}$} & \multirow[b]{2}{*}{$\mathrm{t}$} & \multirow[b]{2}{*}{ Sig. } & \multicolumn{2}{|c|}{ Collinearity Statistics } \\
\hline & & B & Std. Error & & & & Tolerance & VIF \\
\hline \multirow[t]{3}{*}{1} & (Constant) & 3.784 & 1.325 & & 2.855 & .005 & & \\
\hline & Digital Marketing & .078 & .050 & .112 & 1.556 & .123 & .774 & 1.291 \\
\hline & $\begin{array}{l}\text { Keunggulan } \\
\text { Bersaing }\end{array}$ & .908 & .090 & .724 & 10.104 & .000 & .774 & 1.291 \\
\hline
\end{tabular}

a. Dependent Variable: Keberhasilan Usaha

Sumber : Hasil Olah Data SPSS, 2019

Berdasarkan Tabel 7 dapat diketahui bahwa arah hubungan Keunggulan Bersaing ( $\left.\mathrm{X}_{2}\right)$ dengan Keberhasilan Usaha (Y) adalah positif (perhatikan nilai pada kolom unstandardize B), disana tertulis 0.9084 artinya ketika ada peningkatan keunggulan bersaing $\left(\mathrm{X}_{2}\right)$ maka akan meningkatkan Keberhasilan Usaha (Y).

Kemudian penulis melakukan pengujian hipotesis menggunakan uji $\mathrm{t}$ dengan melihat besarnya t hitung dibandingkan dengan t tabel (taraf signifikansi $\alpha=10 \%$ ) kriteria pengujian yang digunakan adalah :.

- Jika thitung > t tabel $(1,296)$ maka $\mathrm{H}_{0}$ ditolak dan $\mathrm{H}_{1}$ diterima.

- Jika t hitung < t tabel $(1,296)$ maka $\mathrm{H}_{0}$ diterima dan $\mathrm{H}_{1}$ ditolak.

Berdasarkan ketentuan yang telah dikemukakan sebelumnya, dimana diperoleh t-hitung sebesar 10,104 dan derajat bebas (n-k-1) atau 100-2-1 = 97 diperoleh angka t tabel 1,296, sehingga t-hitung > t-tabel. Artinya $\mathrm{H}_{02}$ ditolak dan $\mathrm{Ha}_{2}$ diterima, maka terdapat pengaruh signifikan antara Keunggulan bersaing terhadap keberhasilan Usaha (Hipotesis 2 diterima).

Hal ini berarti menjelaskan bahwa semakin baik keunggulan bersaing yang dilakukan oleh UMKM Skala Mikro yaitu memiliki keunikan dibanding produk pesaing, memiliki harga yang lebih rendah dengan pesaing, selalu memberikan inovasi dan adanya layanan tambahan yang selalu memberikan nilai bagi pelanggannya memberikan dampak yang baik pada keberhasilan usaha dai UMKM Skala Mikro tersebut.

\section{Pengujian Secara Simultan}

Pengujian secara simultan dilakukan untuk membuktikan apakah secara bersama-sama Digital Marketing dan Keunggulan Bersaing berpengaruh signifikan terhadap Keberhasilan Usaha.

Tabel 8. Uji Hipotesis Simultan

ANOVA $^{b}$

\begin{tabular}{|ll|r|r|r|r|r|}
\hline Model & & Sum of Squares & df & Mean Square & F & Sig. \\
\hline 1 & Regression & 1060.109 & 2 & 530.054 & 77.126 & $.000^{\mathrm{a}}$ \\
& Residual & 666.641 & 97 & 6.873 & & \\
& Total & 1726.750 & 99 & & & \\
\hline
\end{tabular}

a. Predictors: (Constant), Keunggulan Bersaing, Digital Marketing 
$\operatorname{ANOVA}^{\mathrm{b}}$

\begin{tabular}{|ll|r|r|r|c|c|}
\hline Model & & Sum of Squares & \multicolumn{1}{c|}{ df } & Mean Square & F & Sig. \\
\hline 1 & Regression & 1060.109 & 2 & 530.054 & 77.126 & $.000^{\circ}$ \\
& Residual & 666.641 & 97 & 6.873 & & \\
& Total & 1726.750 & 99 & & & \\
\hline
\end{tabular}

b. Dependent Variable: Keberhasilan Usaha

Dengan nilai $\alpha=5 \%$; df $1=\mathrm{k}=2$; df2=n-k-1=100-2-1=97 diperoleh nilai $\mathrm{F}$ tabel sebesar 3,090. Berdasarkan hasil perhitungan $F_{\text {hitung }}$ diperoleh sebesar 77,126 dengan nilai $F_{\text {tabel }}$ sebesar 3,090. Kriteria pengujiannya adalah, "tolak Ho jika $F_{\text {hitung }}>F_{\text {tabel". }}$ Karena dari hasil pengujian diperoleh nilai $F_{\text {hitung }}=120,975>\mathrm{F}_{\text {tabel }}=3,090$, maka pada $\alpha=5 \%$ diputuskan untuk menolak $\mathrm{H}_{03}$ sehingga $\mathrm{H}_{\mathrm{a} 3}$ diterima.

Jadi berdasarkan hasil pengujian dapat disimpulkan bahwa Digital Marketing dan Keunggulan Bersaing berpengaruh signifikan terhadap Keberhasilan Uaha. Ini berarti bahwa semakin tinggi serta semakin baik digital marketing dan keunggulan bersaing UMKM akan semakin tinggi pula keberhasilan usahanya,.

Hal ini menunjukan bahwa penerapan digital marketing yang baik dan adanya keunggulan bersaing yang di upayakan akan memberikan pengaruh terhadap keberhasilan usaha dimana akan berdampak pada peningkatan omset penjualan, citra yang baik yang terbentuk, adanya efisiesni di produksi, jaringan bisnis semakin bertambah luas, dan nilai asset yang bertambah besar.

\section{KESIMPULAN DAN SARAN}

\section{Kesimpulan}

Berdasarkan dari hasil penelitian, maka peneliti menyimpulkan, tanggapan konsumen mengenai variabel penelitian, sebagai berikut :

1. Variabel Digital Marketing berada pada rentang kategori Baik. Hal ini dapat dilihat dari indikator paling tinggi dan paling rendah,untuk indikator paling tinggi nilai skornya yaitu sudah menggunakan Facebook sebagai saana pemasaran, sedangkan skor terendah pada indicator nama sudah ada pada pencarian search engine.

Variabel keunggulan bersaing berada pada rentang kategori Baik. Hal ini dapat dilihat dari indikator paling tinggi dan paling rendah, untuk indikator paling tinggi nilai skornya yaitu adanya keunikan pada produk yang dijual disbanding pesaing dan selalu ada inovasi, sedangkan skor terendah pada harga lebih rendah disbanding pesaing.

Variabel keberhasilan Usaha berada pada rentang kategori Baik. Hal ini dapat dilihat dari indikator paling tinggi dan paling rendah, untuk indikator paling tinggi nilai skornya yaitu memiliki citra yang baik dan skor terendah pada peningkatan omzet.

2. Terdapat pengaruh signifikan antara digital marketing dan keunggulan bersaing terhadap keberhasilan usaha baik secara parsial maupun simultan.

\section{Saran}

Berdasarkan hasil penelitian yang telah dilakukan, peneliti mengemukakan beberapa saran sebagai berikut : 
a. Skor terendah pada variabel digital marketing yaitu pada indicator nama sudah ada pada pencarian search engine, ini perlu diupayakan dengan memberikan promosi yang intensif dengan berbagai media yang ada baik dengan online maupun ofline sehingga memiliki ekuitas merek yang tinggi yang pada akhirnya akan memiliki urutan yang tinggi saat pencarian di SEO google.

b. Untuk skor terendah pada variabel keunngulan bersaing yaitu pada indikator harga lebih rendah dibanding pesaing, ternyata para pembeli masih menemukan harga yang lebih rendah dari UMKM sehingga perlu diberikan tambahan nilai sehingga efek harga yg lebih mahal tapi adanya tamabahan- tambahan lainnya yag positif sehingga tetap pembeli akan membeli produk UMKM.

\section{DAFTAR PUSTAKA}

Avraham, E., \& Ketter, E. (2008). Media Strategies for Marketing Places in Crisis Improving the Image of Cities, Countries and Tourist Destinations. UK: Elsevier.

Govers, R., \& Go, F. (2009). Place Branding Glocal, Virtual and Physical Identities, Constructed, Imagined and Experienced. England: Palgrave Macmillan.

Kavaratzis, M., \& Ashworth, G. (2010). Towards Effective Place Brand Management Branding European Cities and Regions. UK: Edward Elgar Publishing Limited.

Kotler, P., \& Keller, K. L. (2009). Manajemen Pemasaran (Edisi 13, Jilid 1). Jakarta: Erlangga.

Maheshwari, V. (Vol. 4, No. 2, 2011). Place Branding's Role in Sustainable Development. Journal of Place Management and Development .

Majalah SWA. (2012, 9-26 Agustus). 100 Indonesia Biggest Cities for Business.

Mihalis , K., \& Ashworth, G. (2010). Towards Effective Place Brand Management Branding European Cities and Regions. UK: Edward Elgar Publishing Limited.

Undang-Undang Republik Indonesia Nomor 10 tahun 2009 tentang Kepariwisataan. 